En la España Medieval

ISSN: 0214-3038

http://dx.doi.org/10.5209/ELEM.56083

\title{
Bandos, violencia y poder municipal ante la ausencia de un rey en el en la Corona de Aragón (1410-1412)
}

\author{
Sandra Cáceres Millán²
}

Recibido: 03 de mayo de 2016 / Aceptado: 11de febrero de 2017

Resumen. Durante el Interregno (1410-1412), la Corona de Aragón vive uno de sus periodos más álgidos en cuanto a manifestación de la violencia se refiere; los estados experimentan un vacío monárquico puesto que Martín el Humano muere sin descendencia. Durante este proceso las ciudades no sólo tienen que decidir quién será su rey sino afrontar las múltiples expresiones de los bandos que aprovechan la muerte del rey por hacerse con el control del poder. De esta forma se pretende dar la visión de un periodo desde la perspectiva municipal con la gestión de cada uno de los problemas a los que se enfrenta. Palabras clave: Interregno, Corona de Aragón, violencia, banderías, municipalismo, Catalunya, València, Aragón.

\section{[en] Factions, Violence and Municipal Power in the Absence of a King on the Throne of Aragon (1410-1412)}

\begin{abstract}
During the Interregnum (1410-1412), the Crown of Aragon went through one of its most critical periods in terms of violence, the states lived a monarchic vacuum because Martin the Humane had died leaving no heirs. During this process, towns and cities not only had to decide who their king would be, but they also had to deal with the several attempts of factions in order to take advantage in the control of power after the king's death. The paper sets out to examine this period from the municipalities' point of view, looking at how they dealt with the problems that they had to face up.

Keywords: Interregnum, Crown of Aragon, Violence, Factions, Municipalism, Catalonia, Valencia, Aragon.

Sumario. 1. Introducción. 2. En pos de la estabilidad política: la formación de bandos, la manifestación de la violencia y el bien común. 3. La estructura política de las ciudades: el control de los bandos. 4 . Las grandes ciudades del principado de Catalunya: parcialidades y conflictos. 5. El reino de València y la violencia de sus bandos. 6. El Interregno en Aragón: los casos de Zaragoza y Teruel 7. Conclusiones. 8. Bibliografía.
\end{abstract}

Cómo citar: Cáceres Millán, S. (2017) Bandos, violencia y poder municipal ante la ausencia de un rey en el en la Corona de Aragón (1410-1412), en En la España Medieval 40, 9-34.

\footnotetext{
1 Este artículo ha sido escrito dentro del proyecto financiado por el Ministerio de Economía y Competitividad HAR2012-31484 ““Auctoritas': Església, Cultura i Poder (s. XIV-XV)”. Este artículo no hubiese sido posible sin el apoyo del "Grup de Recerca Consolidat en Estudis Medievals Espai, Poder i Cultura" (2014-SGR 665).

2 Universitat de Lleida sandra.caceres@historia.udl.cat
} 


\section{Introducción}

El 31 de mayo de 1410, el rey Martín el Humano muere sin descendencia directa en el monasterio de Valdonzella. Su único hijo, Martín el Joven, murió en 1409, dejando como único heredero a su hijo nacido fuera del matrimonio, Federico de Luna. El nieto de Martín, nacido al abrigo de una relación adúltera, era a priori el sucesor más deseado por el monarca. Sin embargo, los diferentes movimientos orquestados por cada uno de los bandos, así como su adhesión al resto de candidatos, determinarán un vacío de dos años en cuanto a la ostentación de la corona se refiere.

No obstante, lo que estaba en juego durante este periodo era el modelo de Estado que se quería con la elección del nuevo rey y, sobre todo, el deseo de los súbditos de poder participar más en la toma de decisiones, es decir, tener un lugar en el gobierno desde el cual poder mediatizar la autoridad monárquica. Por tanto, no es congruente afirmar que Caspe fue el clímax de la representación material del pactismo. Sí es cierto que los tres estados que tuvieron representación en Caspe tenían una conciencia política propia que fue capaz de imponer ciertos límites a la política real con el fin de elegir al representante de esos territorios ${ }^{3}$. Con todo, lo que está presente en Caspe no es un acuerdo a tres bandas sino un acuerdo unilateral por parte de Aragón, apoyado por Catalunya y al que es arrastrado el reino de València ${ }^{4}$ por su incapacidad de formar un parlamento propio $y$, por ende, una portavocía con la que sentirse representado. De esta forma se puede entender que no hubo una disputa genealógica sino una discusión sobre quién y cómo se asumiría la soberanía que pretendían los estamentos ${ }^{5}$. Solo de esta forma se puede comprender cómo se involucran en la puga del trono tomando partido por uno $\mathrm{u}$ otro candidato 6 .

Descartado rápidamente el pretendiente francés, todo el ámbito social, económico y político se articulará en torno al de Antequera y al de Urgell, formando dos bandos claramente definidos y muy bien articulados que durante dos años rivalizarán por hacerse con las riendas del poder y proclamar a su candidato como monarca de la Corona de Aragón.

La problemática de los bandos se inserta en un escenario europeo donde el poder se entiende bajo las directrices del pacto y del acuerdo entre monarca y estamentos. Son estos últimos los que envuelven sus intereses con la asunción de una específica representatividad y entran en negociación con los respectivos soberanos, lo cual conlleva el desarrollo de discursos justificativos de base romanista por parte de los involucrados. Es gracias a este precepto que cada uno de los países integrantes de la Corona de Aragón forman un parlamento para debatir dentro de su seno quiénes serán los portavoces, cuáles serán las políticas que se presentarán ante un futuro parlamento común y cómo tendrán lugar a través de la figura del soberano. No obstante, no fue del todo fácil. Mientras que Catalunya y Aragón crearon este parlamento ya claramente politizado y definido a favor de un u otro candidato, en València no hubo resultados al respecto y Mallorca no tuvo ningún tipo de representación ${ }^{7}$.

Furió i Diego, "Un debat inacabat", p. 863.

4 Se utiliza este topónimo ya que desde el 23 de marzo de 2016, el pleno del ayuntamiento de la ciudad decidió que el nombre oficial de la ciudad sea en su denominación catalanoparlante, València.

$5 \quad$ Sabaté i Curull, "Regnat de Martí I", p. 119. El autor afirma que el Interregno pudo haberse evitado si se hubiese tratado de una disputa genealógica, dado que acudir a los archivos para dilucidar quién era el candidato más fuerte hubiese sido fácil para una cancillería plenamente consolidada. Sin embargo, apunta a un bloqueo por parte de aquellos que invocaron la herencia como forma de elección cuando verdaderamente lo que se pretendió por parte de los estamentos fue hacerse con las riendas del futuro.

(Sabaté i Curull, "Per què hi va haver un Compromís", p. 57).

7 El parlamento de València no existió como tal hasta después de la batalla de Codolar (cerca de Morvedre, 
Este hecho no deja de evidenciar la existencia de una deliberación, lo cual indica el carácter participativo de aquellos que pretenden guiar la resolución hacia un candidato u otro. De alguna forma, extraen la soberanía de la corona de lo que significaría la herencia por linaje, de tal manera que ahora son las instituciones las que definen el proceso y lo materializan a través de los parlamentos. Esto no se puede entender sin la autonomía lograda décadas antes a base de privilegios porque ahora, el futuro de los reinos recae sobre unos estamentos que están convencidos de poseer la representatividad de un territorio y su soberanía a causa de este vacío monárquico ${ }^{8}$.

\section{En pos de la estabilidad política: la formación de bandos, la manifestación de la violencia y el bien común}

Los municipios de la Corona de Aragón son el escenario principal donde se desenvuelve el Interregno. En las grandes y pequeñas ciudades se viven nuevas expresiones tanto en el plano político, económico y social las cuales, en muchos casos, adquieren un cariz violento dando lugar a la articulación en clanes familiares. Estos clanes se enfrentarán por el control político municipal dando lugar a la formación de bandos que tienen su origen, principalmente, en el siglo XIV.

Pese a que fuera perseguido todo aquello relacionado con la puesta en peligro del municipio, la ciudad se veía desbordada ante el uso violento del poder que fue mucho más acuciante a partir del siglo XIV. Y es que, desde el siglo XIV y a principios del siglo XV, la urbe intenta no sólo ampararse en su estatus sino también en su independencia como ente jurídico. Pero, sin embargo, son numerosas las ocasiones a las que acude al monarca para detener un problema enquistado en el tiempo y en el espacio. Las ciudades de realengo se encontraban respaldadas por el rey, señor y garante directo, el cual se había convertido en una figura cada vez menos esencial para el devenir político de la urbe. El monarca, desde mediados del siglo XIV, está cada vez más coaccionado por los problemas económicos y por la constante falta de numerario a causa de las diferentes empresas que se llevan a cabo para la consolidación de su figura. De esta manera, se ve maniatado por los avatares de las ciudades que son garantes de la liquidez necesaria para sus objetivos. Así, el rey será cada vez más dependiente de las decisiones municipales y se verá abocado a un mayor sometimiento por la donación de prerrogativas?.

actualmente conocida con el topónimo de origen romano Sagunto) del 27 de febrero de 1412, en la cual combatieron partidarios del pretendiente castellano y catalán dando como resultado la victoria del bando profernandino. Previamente, los bandos valencianos de Centelles (a favor del de Antequera) y Vilaragut (defensores de la causa del conde de Urgell) se reunieron en Traiguera y Vinaròs respectivamente, creyéndose ambos con la potestad oficial de enviar a sus representantes para el parlamento general que tendría lugar en Caspe. De esta forma, finalmente, no tuvieron voz hasta los últimos momentos del Interregno y ni tan siquiera participaron en la denominada Concordia de Alcañiz donde catalanes y aragoneses llegaron a un previo acuerdo para proclamar a Fernando como rey de la Corona de Aragón. Para más información: Mestre, El Compromís de Casp; Bellveser, Els valencians en el Compromís de Casp; Soldevila, El Compromís de Casp; Belenguer, El com i el per què del Compromís.

8 Sabaté, "Per què hi va haver un Compromís", p. 61.

$9 \quad$ Pese a que el papel de las ciudades se veía extremadamente fortalecido con respecto al del rey gracias a alzarse como garantes de parte de los recursos económicos del monarca, muchas veces estas ciudades se encontraban coartadas ante su señor tal como afirma Barraqué, "Construire une identité", p. 67. Barraqué escribe que "d'une manière très ostentatoire, les autorités municipales saisissent toutes les occasions pour manifester leur soumission et démontrer qu'elles entendent être et rester les parfaits sujets soumis au roi'. Los vaivenes en la relación del binomio rey-ciudad son constantes en la pugna por hacerse con el control de los recursos. En este 
Pero, ¿cómo entender las relaciones entre rey y ciudad y esta con su universidad? Desde el siglo XII, con la consolidación del derecho romano, el regimiento público está basado en la universitas que es la que da forma y carácter a la ciudad y está regida por una ley. La universitas se inserta dentro del concepto de res publica la cual, para su buen devenir, ha de tejer relaciones tanto en su interior (en su universitas) como en el exterior con el resto de ciudades y entidades políticas ${ }^{10}$. La unión de cada uno de estos conceptos, ley, universitas y res publica, vuelve a poner en relevancia este derecho romano que empieza a difundirse de nuevo en la Europa Occidental ${ }^{11}$.

La estabilidad de la universitas depende de sus representantes. Son los magistrados o en general la comunidad política la que gestiona todo aquello relacionado con el bien común de la ciudad gracias al amparo del marco legal correspondiente y a la aceptación casi homogénea del mismo. Sin embargo, el bien común se ve sometido a múltiples interpretaciones dependiendo de quien lo defina. Así, por ejemplo, "va desde la justificación de las formas más ilimitadas de autoritarismo regio hasta, por el contrario, la argumentación en favor de medios de control que aseguren la fiscalización automática y sistemática del poder real”'12. El alto nivel de adaptabilidad del concepto ha hecho que haya sido visto como "la traque de la formule a pu ainsi montrer que le Bien Commun n'était pas qu'un stéréotype de la littérature et des pratiques politiques du temps" ${ }^{13}$.

sentido, otros autores indican la constante sospecha de muchos municipios hacia un rey que "empentat per les imperioses necessitats econòmiques, s'aboca de manera creixent a cercar quantioses injeccions crematístiques mitjançant tant una abusiva interferència amb la justícia ordinària, en concedir canvis de fur, llicències, guiatges, remissions etc. Com recurs a una veritable fiscalitat encoberta mitjançant concessions a municipis que comporten importants exigències econòmiques" es decir que, mientras el municipio avala económicamente al rey, es el monarca quien intenta recuperar su peso político en la gestión de políticas de carácter municipal. Para conseguirlo, el rey instaura en cada uno de los núcleos de población más importante una figura que lo representará de forma diaria como es el caso del veguer en Catalunya. (Sabaté, "Discurs i estratègies del poder reial", p. 636).

10 Ladero, "Poderes públicos en la Europa medieval", p. 21. La "cosa pública" será tratada como una herramienta a través de la cual los municipios más importantes van a vertebrar tanto a su población como a otras tantas de su alrededor para lograr la constitución de un gran centro de influencia política. Esto se consigue gracias a la gran independencia lograda a través de las prerrogativas reales. Esta autonomía se va a mantener con los recursos de la gestión de un territorio considerable y el control sobre otros señoríos y villas más pequeñas (Watts, $L a$ formación de los sistemas políticos, p. 224).

11 Detrás del derecho romano se hallaban los principios de ley natural (relacionados más o menos con los 10 mandamientos) y el derecho de las naciones (ius Gentium) que se refería al derecho de propiedad, al carácter sagrado de las promesas y a los principios de justicia en actos de compra, venta, préstamos, enajenación, cesión y arrendamiento (Black, El pensamiento político, p. 136). A partir de la difusión del derecho romano, los dominios del monarca y su regalía eran simplemente una herencia cuya preservación era responsabilidad del rey y de todos, puesto que eran necesarios para gobernar el reino (Watts, La formación de los sistemas politicos, p. 93). Otro ejemplo lo aporta Barrio (Barrio, "Que als dits ordenaments...", p. 254) en el que enmarca al reino de València en un complejo sistema de relaciones políticas, sociales y económicas que se dan entre los diferentes municipios, "se configuraban sobre parámetros como el bien común general de la monarquía y del reino y el bien común y el servicio público de los vecinos hacia su propio municipio".

12 Nieto, Propaganda política y poder real, p. 495.

13 Lecuppre-Desjardin, van Bruaene, Introduction: le Bien Commun, p. 2. Ambas autoras añaden que "CEuvrer dans l'intérêt général semble être inhérent à toute société, mais agir au sein de la communauté, c'est aussi façonner des comportements, proposer des lignes de conduite et créer une sorte de dénominateur commun (...). Le Bien Commun -sa poursuite, sa pratique- ne tend pas ver la construction d'une société égalitaire ; il s'adapte aux réalités de son temps et cautionne les hiérarchies et les déséquilibres inhérents à ces communautés médiévales, il permet même de déceler des groupes de pression". De esta forma, se demuestra la extrema fragilidad de un concepto al que se recurre constantemente por parte de las entidades políticas. Este concepto es un instrumento utilizado al servicio de aquellos grupos que persiguen ciertos intereses y apelan al papel paternal de la sociedad para la misma sociedad. 
El bien común, en manos de los municipios, se entiende como una expresión de una identidad común de todos sus habitantes y, por tanto, la razón de ser de la autonomía urbana ${ }^{14}$. Así, una de las cosas primordiales para las urbes es la aceptación exterior de su categoría. El hecho de ser reconocidos como ente único e indisoluble les hará llegar a múltiples escalafones de negociación en diferentes ámbitos de la política no solo con su señor más inmediato sino también con el resto de municipios de los reinos. De esta forma, si la universitas y sus representantes son lo suficientemente estables y fuertes, las prerrogativas y el radio de influencia es mucho mayor logrando así un mayor reconocimiento, erigiéndose como municipios clave a los que acudir cuando existe algún tipo de problema como más adelante se verá con el Interregno. Esto no sería posible sin el visto bueno del monarca ya que es éste quien les reconocerá una capacidad municipal que las facultará a un mayor ordenamiento interno y, lo que es más importante, el municipio es aceptado como interlocutor en las diferentes negociaciones ${ }^{15}$.

De este modo se entiende como, progresivamente a lo largo del siglo XIV y principios del XV, los gobiernos municipales tienden a desarrollar estrategias con el fin de alcanzar mayor homogeneidad en su conjunto y, sobre todo, mayor consolidación en materia jurisdiccional ${ }^{16}$. Esto se logra a través de la promulgación de privilegios no solo en su término sino en su misma región y área de influencia obteniendo así mayor inalienabilidad y creando un conjunto mucho más fuerte, dado que se ha logrado la absorción de entidades menores a cambio de mayor protección ${ }^{17}$.

Otro aspecto a tener en cuenta es la influencia de pensadores y literatos que analizaron la sociedad de su entorno ${ }^{18}$. Un ejemplo muy importante que la Corona de

14 No hay que olvidar que parte del discurso que utilizan los municipios nace del discurso del monarca, todo ello para mantener la concordia de sus habitantes: "En maîtres de la ville, qu'ils qualifient quelque fois de res publica, les dirigeants urbaines peuvent se servir des mêmes stratégies argumentatives et arguments juridiques que la royauté emploi à leur propre égard" (Naegle, "Armes à double tranchant?”, p. 59).

15 Una de las cosas primordiales para los municipios es la aceptación exterior de su categoría. El hecho de ser reconocidos como ente único e indisoluble les hará llegar a escalafones de negociación en diferentes ámbitos de la política no solo con su señor más inmediato sino también con el resto de municipios de los reinos. Para más información del tema: Sabaté, "Identitat i representativitat social"; Cawsey, "Reialesa i propaganda".

16 La articulación política e institucional de las ciudades era esencial y por tanto, debía de crearse un programa cívico, donde los habitantes respetaran, mediante el consenso, la vida pública de su ciudad. Para la elaboración de este programa o ideario se "utilizaron procedimientos y liturgias también sagradas, pretendiendo exhibir y proclamar el poder de las instituciones ciudadanas, crear un consenso político entre la población urbana, concitar una opinión pública favorable y al mismo tiempo afirmar la posición privilegiada de las oligarquías urbanas" (Narbona, "Ideología y representación”, pp. 112-113”).

17 Esto no solo ocurre en los municipios de la Corona de Aragón. En Francia las bonnes villes (municipios que servían a la corona como centros gubernamentales y fiscales a cambio de la concesión de privilegios varios) se fortalecieron aumentando su autonomía fiscal y les proporcionó una posición más preminente en el sistema político. Con ello, se forman una serie de redes independientes que pueden desafiar la política fiscal real de manera exitosa tal como ocurrió entre 1379 y 1382 en Francia y en la Corona de Aragón en torno a grandes capitales como Barcelona, Zaragoza, Mallorca, València o Perpiñán (Watts, La formación de los sistemas políticos, p. 297).

18 El análisis del bien común como concepto social va íntimamente ligado con grandes pensadores del siglo XIII. Tomás de Aquino entendía el bien común como el bien de todos los miembros en contraposición de uno o de unos pocos. Era el principio del altruismo ampliado dentro de los límites de un estado determinado (Black, El pensamiento político, p. 39). Siguiendo los preceptos de Aquino y en su obra "Defensor Pacis" Marsilio de Padua aspiraba a poner remedios a todos los males de los estados bebiendo de las ideas de Aristóteles. Entiende el gobierno como una concesión la voluntad divina aunque la autoridad última descansaba en la asociación de ciudadanos o en el pueblo que, a veces podía ejercer esa autoridad por sí misma. Para Marsilio de Padua, la parte gobernante tiene como objetivo regular los actos civiles humanos mediante la ley. De esta forma, el autor, entiende el bien común como aquello que la mayoría del pueblo desea y es la acción legislativa por parte de ese mismo pueblo y no de forma unilateral (Black, El pensamiento politico, p. 90-100). 
Aragón albergó entre los jurados de las principales ciudades de los reinos fueron las obras de Francesc Eiximenis. Este autor en su Dotzè o El Regiment dels prínceps e de comunitats (escrito entre 1383-1391) compila y despliega toda la doctrina relacionada con el sistema de regulación del poder. El autor presenta el poder político como una consecuencia que deriva de la piedad divina puesto que Dios es la causa remota y origen inmediato del poder. En su obra aboga por el entendimiento entre príncipe y pueblo y este se logra a través de los pactos ya que son estos mismos los que definen y limitan el poder para que prevalezca siempre el bien común ${ }^{19}$. Y es que "la ville est un lieu d'exercice politique (...) la loi et son respect tiennent une place essentielle. Si les grands n'observent pas la loi, les autres ne l'observeront non plus" ${ }^{\prime 20}$. Es por esto que Eiximenis insistió tanto en la guarda de la res publica, que la acabó asociando al bien común, puesto que la existencia de una organización social exige la presencia de algún tipo de regimiento que establezca su adecuada ordenación "car poble de sí mateix no ha regiment" 21 . Asimismo, Francesc Eiximenis entendía el concepto de res publica como "una comunitat de gents ajustades e vivents sots una mateixa llei e senyoria, e costumes" 22 . Además, el franciscano afirma que todas las ciudades del mundo "en llur fundació foren primerament paccionades e posades en certs pactes" lo cual no hace sino avalar la representatividad colectiva ${ }^{23}$.

El pensamiento político y social de Eiximenis no deja de estar en consonancia con los antiguos modelos escolásticos universitarios y existe cierta simbiosis con el pensamiento aristoteliano y el agustinismo, siempre adaptando su pensamiento a las circunstancias de la Corona de Aragón. No es de extrañar que, por ejemplo, los jurados de València pidieran al franciscano un tratado para el regimiento de la ciudad dando lugar a la creación de Regiment de la cosa pública y desde Barcelona llegara Lo dotzè del crestià, una suma teológica escrita para el rey y el consell de Barcelona la cual contenía una visión de la sociedad que "se ha considerado como la primer articulación del pactismo, es decir, la noción de que la autoridad política justa descansaba sobre un contrato entre el gobernante y los súbditos, para el bien

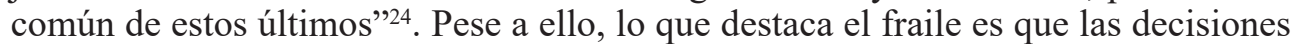
políticas no deben pertenecer a las mayorías ya que las decisiones se desprenden de los representantes de la universidad y no de la misma comunidad añadiendo que "la multitud del pueblo debe ser apartada del gobierno de la ciudad"25.

Así, las ciudades intentaron absorber el influjo de estos pensadores que construyeron su discurso y fue adaptado a las necesidades de los municipios. No solo

19 No sólo era una cuestión que tenía en cuenta Eiximenis. En toda Europa se extiende una especie de lenguaje cívico que remite a la voluntad común de todos los ciudadanos. La aplicación de estos nuevos conceptos en la ciudad y en su gobierno daba lugar a que "cuando se alcanzaba el consentimiento común no basta con sondear a los individuos por separado en sus hogares, se debe tener el consentimiento de todos al mismo tiempo en una asamblea (Ibidem, p. 183). Previamente, Juan de Salisbury en su "Policratus" entendía "unlike his predecessors, who treated the Principe as a particular person whose authority rested on fealty, John [of Salisbury] equated "the prince" with "the public power", whose authority corresponded to a specific territory" (Taylor, "John of Salisbury, the Policratus...", p. 140).

20 Barraqué, "Les idées politiques de Francesc Eiximenis", p. 553.

21 Juncosa, "Pensar el pacto en la Corona de Aragón".

22 Barraqué, "Les idées politiques de Francesc Eiximenis", p. 540.

23 Sabaté, "Regnat de Martí I", p. 76.

24 Watts, La formación de los sistemas políticos, p. 281.

25 Narbona, "La idiosincrasia de las sociedades urbanas", p. 309. Con ello, Eiximenis, no niega el pacto entre gobernador y gobernados, sino que este pacto se realiza con la intención de dejar las decisiones en manos del soberano, que lo es gracias a sus súbditos. 
fue un recurso adoptado por la Corona de Aragón ya que en toda Europa el bien común sirvió de amalgamador y nexo de unión para la construcción de una sociedad más fuerte y consolidada ${ }^{26}$. Sin embargo, la instrumentalización de dicho concepto proyecta imágenes muy diferentes de las de su definición original. Pese a que las grandes ciudades de la Corona de Aragón lucharan por concentrar los pareceres y opiniones de sus élites, esto no llegará a buen puerto dada la importancia que adquirieron los bandos en la articulación política municipal. Las facciones continuarían siendo una influencia en el regimiento político la cual es más acusada en períodos de mayor incerteza como el Interregno.

\section{Estructura política de las ciudades: el control de los bandos}

A principios del siglo XV, Europa vive un momento donde el acuerdo es la base del sistema político gracias a la consolidación de todos los preceptos romanos enumerados anteriormente. Los estamentos ya han asumido una gran representatividad a través de la negociación con sus soberanos y es en el municipio y desde él donde se han tejido estas convergencias y desavenencias. Sin embargo, ¿qué ocurrió tras la muerte de Martín el Humano? No existe una explicación unívoca para entender el bienio que vive la Corona de Aragón. Formada por territorios con leyes independientes pero con un denominador común, el rey, las principales ciudades, junto a grandes figuras políticas como son los gobernadores, bailes, justicias o jurados, son las que llevan adelante políticas que intentan mantener en jaque el vacío regio ${ }^{27}$. Pese a ello, existe una profunda división articulada en torno a los candidatos y esto marcará el ritmo político durante el Interregno, ya que "las afiliaciones a uno u otro candidato se realizarán como opciones de bando" 28 .

Los bandos se han de entender como linajes que estaban conformados por una extensa comunidad unida entre sí por lazos de sangre o solidaridad antropológica los cuales comparten unos intereses comunes. La división social en bandos responde a un mecanismo de solidaridad propio de la baja Edad Media y la inserción de los individuos en estas facciones se hará con un objetivo claro y es el de la solidaridad para con el resto de miembros del grupo ${ }^{29}$. Amici et parenti son partes indispensables de la solidaridad y del papel del individuo dentro de cada bando. De esta forma se puede observar que tras cada acto no hay un único individuo sino todo un conjunto de parientes (de sangre o no) que responderán como un bloque único. Esto dará lugar a una serie de respuestas por la gran envergadura que cobra el conflicto dado la confianza y el apoyo que reciben unos y otros por parte del clan o bando ${ }^{30}$.

26 "Medieval princes considered the idea of equality as a useful tool for social peace within their countries. King Henry III of England used it in one of his ordinances in 1267: 'all citizens, rich and poor, are as one body" (Prevenier, "Utilitas communis in the low countries", p. 210). Desde finales del siglo XIV, en Europa circula una idea clara y es que el objetivo principal del gobierno debía ser el bienestar común de las personas que presidia y que estas requerían gobiernos.

27 Tras la recuperación del Regne de Mallorques por parte de Jaime II en 1319, durante las cortes de Tarragona, se aprobó el Privilegio de Unión, por el cual se consagraba la indivisibilidad de la Corona de Aragón. Desde entonces, el rey debía jurar mantener la unidad y si faltaba a su juramento los estados podían resistirle por la fuerza (De Francisco, "Jaime II y la 'Constitución"”, p. 522).

28 Sabaté, "El Compromiso de Caspe", p. 285.

29 Sabaté, "Les factions dans la vie urbaine", p. 340.

$30 \quad$ Ibidem, p. 344. 
La formación de estos grupos viene marcada, en primer lugar, por el aumento de la autonomía de la ciudad y la participación de estos clanes en el devenir político y al frente de las instituciones que la representan ${ }^{31}$. Estas facciones actúan siguiendo una línea que agrupa a todos los miembros en torno a un mismo objetivo, involucrando a personajes de estamentos inferiores hasta a los representantes o las cabezas visibles del partido que acostumbraban a frecuentar los cargos más importantes de la ciudad o, incluso, en torno a la figura del monarca ${ }^{32}$. En este caso, durante el Interregno, estos bandos están al frente de los núcleos de población más importantes del reino haciendo valer su autoridad o sus intereses frente al resto de facciones que rivalizarán por hacerse con el monopolio de la gestión municipal ${ }^{33}$.

Con todo, este periodo de inestabilidad no resulta tampoco nuevo en el territorio:

les difficultés sociales et économiques causent les graves conflits de la deuxième moitié du siècle [XIV], mais le climat était déjà très tendu dans les décennies antérieures, par la dynamique-même de la solidarité clanique ${ }^{34}$.

Con el crecimiento de las urbes como lugar de mayor apogeo económico, nuevos grupos sociales tienen acceso a nuevas cuotas de poder, produciéndose un gran conflicto entre aquellas élites enquistadas siglos atrás con estos nuevos burgueses. El hecho de querer acceder a estas parcelas de poder por parte de estos grupos constata la poca evolución del sistema de acceso y el hermetismo de unas élites que ahora ven peligrar su influencia ${ }^{35}$. Pese a que los representantes de la universidad experimentan una mayor presencia y representatividad gracias a la mayor autonomía política que asumida a raíz de los diferentes pactos y estrategias que se desarrollan en un marco político cada vez más negociador, esto no deja de evidenciar el anquilosamiento que hay dentro de los sistemas de elección pese al gran abanico de variedades que existen. Los sistemas de elección municipales son un reflejo de la situación. Pese a ello, cada sistema elección genera el enquistamiento de determinadas familias en determinadas parcelas y sectores de poder lo cual favorece la agitación de aquellas que también quieren hacerse hueco en la política y no pueden acceder. ${ }^{36}$ Es así, mediante la ocupación de cargos de diferentes niveles, como estas élites van asumiendo

31 Tal como apunta R. Narbona "la vertebración del clan familiar surgirá de la lucha por el control de la municipalidad de la detención prolongada de puestos públicos en el gobierno urbanos y de la puesta en marcha de un proyecto político en el marco del gran negocio urbano que constituye la misma ciudad" (Narbona, "Gobierno político y luchas sociales", p. 85).

32 "Les factions étendent des ramifications qui s'engagent dans un conflit selon sa gravité particulière, les antécédents et les moyens du groupe", Sabaté, "Les factions dans la vie urbaine", p. 340.

33 "A lo largo del siglo XV los bandos minan la convivencia en la mayoría de poblaciones. La respuesta agresiva se inserta en el conjunto social" (Sabaté, "Orden y desorden...”, p. 1398).

34 Sabaté, "Les factions dans la vie urbaine", p. 378.

35 Muchas veces, el motivo principal de la disputa entre facciones no se trata de única y exclusivamente el del deshonor o brega hacia el bando enemigo. La política, su gestión, su inserción y su monopolio fue una de las causas por las que los bandos en Tarragona, por ejemplo, empezaron a desarrollarse en el último cuarto del siglo XIV. El fin último era "hacerse con el control del municipio y acabar con la dualidad de poderes en la cúspide su señorío" (Juncosa, "Muyren los traydors!...”, p. 463). Este caso es mucho más problemático que otros puesto que la ciudad pertenecía también al arzobispado y, por lo tanto, era de carácter eclesiástico y real, al contrario de lo que muchos miembros deseaban, esto es, pertenecer en exclusiva al realengo. Esto no era más que "un reflejo más de las tensiones político-institucionales protagonizadas por sus señores quienes, más que como árbitro, actuaron, a menudo, ejerciendo un papel de primer orden como sus promovedores" (Ibidem, p. 463).

36 Con ello se forma una "oligarquía endogámica de familias reproducidas en el ejercicio de las más relevantes competencias y cargos" (Narbona, "Cultura política y comunidad urbana", p. 180). 
la representatividad de su universidad y la van heredando de padres a hijos dando por corrompidos estos sistemas de elección que pronto se estancan y hacen estallar de nuevo los problemas entre sus habitantes ${ }^{37}$.

Sin embargo, la consolidación del pacto entre el patriciado y el monarca hace que los consejos de las ciudades devengan un elemento clave para la puesta en marcha de políticas que responden a las demandas intrínsecas de la sociedad. En las representaciones de las universitas hay un objetivo claro y es el de mantener la paz y tregua dentro de su municipio y, si tiene, en su área de influencia. Y es que los desórdenes se suceden en el tiempo y se heredan en cada una de las familias que forman parte de la ciudad. Es precisamente a través de la representación donde se puede observar cómo esas familias que ostentan un cargo hacen valer su fuerza y su linaje a través de la posición que ocupan y no de forma nominal. Es decir, en determinadas ocasiones utilizan su cargo político para hacer valer sus intereses y de esta forma hacerse con las riendas de la política urbana ${ }^{38}$. Y es que estos conflictos se producen por la existencia de intereses contradictorios entre grupos. El antagonismo no es suficiente para que la lucha estalle ya que, además, es necesario que un grupo determinado tome conciencia de la situación asumiendo la reivindicación frente a su antagonista y este es el caso de las familias imbricadas en cada uno de los gobiernos municipales ${ }^{39}$.

La conflictividad, es palpable en todos y cada uno de los territorios de la Corona de Aragón y tienen su escenario en las ciudades y villas más importantes de los territorios $^{40}$. De este modo, y como se verá a continuación, las grandes capitales como Barcelona, València o Zaragoza, y otras ciudades importantes de los reinos como Girona, Lleida, Teruel, Castelló o Alzira viven en su seno la representación máxima de una violencia que, se insiste, viene ya heredada de décadas atrás. En muchos de estos municipios, aunque parezca inverosímil, los bandos serán un acicate para el control de los conflictos y un mecanismo de estabilidad que pretende acabar con la violencia.

Los motivos que llevan a unos grupos u otros a emprender acciones son muy diversos. Los más habituales son aquellos en los que se ponen en tela de juicio los resortes de poder del grupo dominante a los cuales quieren acceder aquellos que quieren experimentar la gestión del poder ${ }^{41}$. Por otro lado, las jurisdicciones, el aca-

37 Esta representatividad era esencial no solo en los aspectos políticos municipales internos sino también en los externos donde por ejemplo (aunque no en este contexto) aparece la figura del rey el cual acepta a estos representantes y les reconoce "una capacitat municipal, els faculta la capacitat d'ordenament intern i els accepta com interlocutors" (Sabaté, "Identitat i representativitat", p. 73).

38 Para entender el porqué de estas élites y el porqué de su participación e inserción en bandos: Iradiel, "Señoríos jurisdiccionales y poderes públicos", p. 83. "Distinguir en la práctica política bajomedieval cuánto hay de privado y cuánto de público no sólo corre el riesgo de producir anacronismo sino de viciar, de entrada, una cuestión tan decisiva como determinar qué papel político de la nobleza bajomedieval medido por el doble baremo del declive de la riqueza señorial y de la mayor o menor presencia de los nobles en los distintos ámbitos de lo público y estatal".

39 Valdeón, "Los conflictos sociales en los siglos XIV y XV”, p. 134.

40 Mackay, "La conflictividad social urbana", p. 509. El autor entiende que "también es posible detectar en algunos bandos la existencia de ideologías propias que los convierten en algo respetable, honorable y digno de alabanza" (ver página 512).

41 Tanto en la Corona de Aragón como en otros territorios de Europa como es Castilla, el grupo dominante se ve asediado desde dos flancos: "se presenta agredido desde arriba por linajes, bandos y grupos nobiliarios, mejor equipados y más dispuestos que el resto de grupos para la revuelta, la sedición o el conflicto. Pero también es agredido desde abajo por los grupos medios y menores (profesiones liberales, mercaderes, artesanos, incluso caballeros desplazados e hidalgos sin fortuna) que se constituyen en "común" o "comunidad" y que se apoyan en diversas formas de sociabilidad profesional, corporativa o religiosa" (Iradiel, "Formas del poder y de organización", p. 40). 
paramiento de prerrogativas, la asunción de un mayor cuerpo de funcionarios frente a otras ciudades, la extensión del área de influencia y jerarquización de las poblaciones son algunos de los otros motivos por los que se entra en conflicto, un conflicto que en el siglo XV queda más confinado al interior de los estados que no de cara al exterior como muestran los dos años de vacío monárquico ${ }^{42}$.

Previamente, durante el gobierno de Martín el Humano el espacio real retrocedió espectacularmente perdiendo fuerza en el diálogo y, sobre todo, en el ámbito económico $^{43}$. El pactismo podría explicarse a raíz de la adaptación al contexto y es fruto del equilibrio entre grupos de presión que poco a poco van tomando las instituciones ${ }^{44}$. Estos grupos de presión se articulan en torno a estos partidos que harán tambalear la justicia de cada uno de los núcleos poblaciones y, lo que es más importante, ponen en tela de juicio el sistema judicial el cual es considerado largo y costoso a raíz de las garantías romanistas. Sin embargo, estos núcleos no cuestionan la solidaridad como forma de hacer frente a las demandas del rey pero, con todo,

la contundència de les topades en témer les conseqüències crea un clima de tensió física la qual cosa, dissuadeix a invertir [en el municipio] i de participar al mercat i a la fira. Tampoc ajudarà a atraure població ${ }^{45}$.

Además, con la muerte del rey Martín y durante el Interregno, las ciudades no solo luchan por estabilizar su propia universidad sino también por hacerse con las riendas de los reinos a los que pertenecen sin importarles competir con otras ciudades vecinas para dirimir soluciones de unos problemas que no nacen con la ausencia del monarca sino que, con su muerte y en algunos casos, estallan de manera definitiva.

\section{Las grandes ciudades del Principado de Catalunya: parcialidades y conflictos}

En Catalunya, las principales ciudades del Principado se ven sometidas a los avatares de este periodo. Estas grandes urbes lidian con pequeños núcleos para mantener no solamente su estatus sino también para emerger como garantes plenas de una estabilidad que antes se antojaba lejana y que ahora está aun más truncada. En el caso del Principat existe una gran capital, Barcelona, sede de referencia para la Corona

42 Watts, La formación de los sistemas políticos, p. 402. Tal como asegura John Watts "el aumento de la separación entre la política interna y las guerras y la diplomacia externas realzó la tendencia centrípeta de los sistemas políticos del siglo XV, lo que ayudó a estabilizar la política al asegurar que los conflictos quedaban más confinados al interior de las fronteras "regnales": las guerras civiles de mediados del siglo XV implicaron, generalmente, muchas menos intervenciones transfronterizas que las del XIV".

43 Sabaté, "Regnat de Martí I", p. 70-71. El autor, además, señala el importante vacío que existía en las arcas reales dando lugar a que el rey estuviera permanentemente en negociación con los estamentos que son los que ahora poseen la capacidad económica y recuperan, progresivamente, la capacidad municipal en detrimento de la monarquía. E. Guinot, a su vez, afirma que "les raons de la crisis del patrimoni reial i les dificultats constants de la hisenda pública durant bona part del tres-cents foren més estructurals, de model d'hisenda pública dins el marc del llarg procés de creació d'una veritable fiscalitat d'estat. Cal incidir en la importància de llargues guerres en les quals es van veure involucrats la Corona i els regnes catalanoaragonesos" (Guinot, "Sobre la gestió del patrimoni", p. 275).

44 Se entiende el poder del soberano como único e indisoluble aunque siempre relativizado por contrapoderes que no tienen la intención de eliminarlo de la esfera política sino de integrarlo en una nueva definición que estará al servicio de cada una de las conspiraciones políticas que se van produciendo a lo largo de estos años (Belenguer, El com i el per què del Compromís, p. 86).

45 Ibidem, p. 100. 
de Aragón y capital política de todo el territorio. A ello se le une el nombramiento de 12 consellers que tratarán de monopolizar el proceso gracias a que ellos consideraban que poseían plena legitimidad, puesto que eran representantes de la ciudad más importante del principado y una de las más importantes de la Corona de Aragón. Barcelona, además, es el lugar donde se encuentran la mayoría de instituciones del país, entre la que destaca la del Gobernador, cargo encabezado por Guerau Alamany de Cervelló militante declarado del bando castellano.

A todas estas circunstancias, se ha de unir el hecho que, tras la capital del Principado, existe la fuerza y empuje de otras ciudades como Lleida, que intentarán mediatizar el papel de la urbe y cuyo antagonismo llega a conflictos diplomáticos ${ }^{46}$. $\mathrm{Y}$ es que, si algo hay importante en este bienio, es la tensión que existe entre las ciudades no solo por imponerse como garantes de un proceso sino por hacer valer su idiosincrasia frente a aquel que pueda perturbar la estabilidad dentro de sus murallas o en su área de influencia.

Son numerosos los conflictos que se dieron, pero de ellos se desprenden dos hechos muy importantes. Por un lado, la absorción cada vez más rápida de un territorio de influencia que ahora es controlado por políticas creadas desde la metrópoli y que subyugan a entidades menores a los azares de la gran ciudad ${ }^{47}$. Por otro, la permanente disensión entre grandes ciudades y la creación y consolidación de nuevos pactos con otras de carácter menor pero no menos importantes para contrarrestar el papel de la capital y delimitar su radio de acción.

Sin embargo, lo que más preocupa a las ciudades de Catalunya es la existencia de reyertas, bandos y manifestaciones violentas dentro de sus murallas. No se trata de una inquietud nacida por la ausencia del rey sino de una fractura que viene arrastrándose desde tiempos atrás. En 1405, la prolongación de las cortes en Perpiñán, Sant Cugat y Barcelona evidencia la actuación un tanto cuestionable de la sociedad política catalana:

la falta de voluntad por impulsar cambios y un proyecto común, y su incapacidad para interesarse por los serios problemas que afectaban al Principado dio como resultado su pérdida de peso político en el conjunto de la Corona de Aragón ${ }^{48}$.

En el caso de Lleida existen dos grandes bandos organizados alrededor de las familias Sescomes y de Navés. Los primeros, fernandinos, y los segundos, urgelistas,

46 Los Paers (magistrados) de Lleida denuncian ante el gobernador la situación. Lleida cree que desde Barcelona se está acaparando todo el proceso y se toman las decisiones sin consultar con el resto de municipios de realengo del Principat: "volent la dicta ciutat de Barchinona ésser cap i membre de tota Cathalunya". A inicios de este periodo, estas desavenencias son más acusadas e incluso llegan a desencadenar gran desafección por aquellos que trabajan por la preeminencia de Barcelona (Arxiu Municipal de Lleida-en adelante AML-Correspondència, 842 , f. 14, 1410, junio 21).

47 El municipio de mayor envergadura atrae a los núcleos menores con su atractivo inherente al ofrecer privilegios y mayor solidaridad a la población acogida. Esto permite tratar como propios a los habitantes de las poblaciones sometidas que a cambio pactan una aportación. Este pacto es conocido como "carreatge" y se entiende como una garantía de estabilidad. De esta forma, la ciudad recibe en propiedad los lugares afectados y sus habitantes, a la vez, han de ofrecer un juramento de fidelidad (Sabaté, "Municipio y monarquía", pp. 35-36).

48 Esta es una de las razones por las que el Parlamento de Catalunya se deja guiar por Aragón en el proceso de elección de monarca en la concordia de Alcañiz y en el posterior Compromiso de Caspe. La incapacidad de los parlamentarios en la toma de decisiones y en la puesta en marcha de nuevos objetivos son el resultado del enquistamiento de familias en la ocupación de cargos tanto a nivel municipal como estatal y el controvertido sistema de elección de cargos (Sesma, "La fractura en la sociedad política...,", p. 1045). 
rivalizaron hasta extremos mortales pese a que fuera reiterada la demanda de ayuda al gobernador, Guerau Alamany de Cervelló, para intervenir en el conflicto ${ }^{49}$. La ciudad, por su parte, toma cartas en el asunto con la prohibición de llevar armas al cabeza del bando Sescomes, Ramon de Sescomes, al cual inhibe atacar y "dampnegar los lochs d'Alfés, Súnyer e Tabach qui són en salvaguarda del senyor rey e en vehinatge de la ciutat" que, curiosamente, pertenecen a Samsó de Navés, cabeza de linaje de los Navés ${ }^{50}$.

Otros actos de alzamiento contra la ciudad por parte de grupos rebeldes serían los de aquellos que renuncian y rompen con su vasallaje. Conocido como deseiximent en la documentación en lengua catalana, Lleida sufrió por parte de algunos donceles este tipo de actos que no hacían sino evidenciar el aprovechamiento de un contexto que, a priori, podría ser resultado de un vacío político ${ }^{51}$. Otro ejemplo de conflicto a los que se ve sometida la ciudad relaciona diferentes jurisdicciones a distintos niveles políticos. El 13 de junio de 1411 Lleida pide al oficial de Tarragona que actúe contra Ramon de Palleres porque intentó hacerse con la rectoría de Cubells de la cual la ciudad es señora:

lo dit en Ramon vench un jorn a la dicta església de Cubells ab lurs sequaces en menyspreu del dit loch. E ésser a missa major, lo prevere vestret e lo ofici en la església solempnialment celebrant, ma armada e ab pensa deliberada e hàbit laical, se mes en turbar lo ofici dient que ell prendrie la possessió del dit loch ${ }^{52}$

Sin embargo, el punto álgido al que se enfrenta la ciudad es con la muerte de Samsó de Navés, fruto del asesinato por parte de Ramon Sescomes. En este momento la ciudad, al límite de su capacidad de respuesta, pide ayuda de forma muy reiterada tanto al gobernador como al mismo parlamento de Catalunya, reunido para deliberar sobre la elección del nuevo rey ${ }^{53}$. A ello se le unen las constantes noticias que diferentes municipios como Fraga o Barbastro que avisan de la presencia de tropas gasconas al norte de los Pirineos pagadas y capitaneadas por Jaume d'Urgell o la presencia de castellanos en la frontera con Aragón ${ }^{54}$. De este modo, por parte de la ciudad, se tejen una serie de relaciones a través de la correspondencia con dichos municipios con el fin de colaborar para salvaguardar todos los territorios de la Corona de Aragón pertenecientes al patrimonio real. Con otros tantos, la diligencia es

49 AML. Correspondència, 842, f. 58v (1410, noviembre 15). En su carta, piden al gobernador algún oficial para terminar con las banderías "per esquivar los dits sinistres e destruccions de la ciutat és vist molt necessari que ací vingue alguna persona notable e esforçada ab poder bastant per punir e castigar los mals fets e refrenar los atrevits e posar pau e tranquil·litat e en bon regiment de la cosa pública".

50 AML. Correspondència, 842, f. 35v (1410, agosto 14).

51 AML. Correspondència, 842, f. 64. Gispert de Cervelló, doncel, en el lugar de La Llacuna, rompe con el vasallaje al baile de La Llacuna, Joan Ferran. Esta villa es de la señoría de Lleida pero muy próxima a Igualada. El doncel “en les nits proppassades eren estades posades dues cèdules de paper la una en les portes de l'església parroquial de sant Johan i l'altra en les portes de l'habitació del dit Johan [Ferran]". (1410, enero 11).

52 AML. Correspondència, 842, f. 123v (1411, junio 13).

53 "Us requerim per salvar aquesta ciutat" o "vos supplicam axí cordialment com podem, sia vostra mercè de rescriure-li donant-li consell e de fer-li vostra resposta cuytadament e tal que nosaltres e aquesta ciutat siam preservats de perills e sinistres versemblants" son algunas de las súplicas que dirigen al gobernador, Guerau Alamany de Cervelló, y al parlamento respectivamente (AML. Correspondència, 842, f. 153 -1411, agosto 24y f. $158-1411$, septiembre 11-).

54 AML. Correspondència, 842, f. 162 (1411, septiembre 15); f. 166 (1411, septiembre 24); f. 166v (1411, septiembre 25), f. 178v (1411, noviembre 6). 
esporádica pero no menos importante al tratarse de núcleos situados muy cerca de las fronteras.

Con Puigcerdà, ya en la frontera con Francia, el 22 de noviembre de 1411, se establece una mayor correspondencia a raíz de la presencia de estas tropas gasconas que, ya presuponían, eran pagadas por el conde: "no saviets certament a mà de qui ni de qui no, mas és presumidor que la llur entrada se faça a mà d'algú dels competidors dels regnes e terres de la Corona d'Aragó" 55 . Hecho ya el aviso, el siguiente paso es informar al resto de villas con las que la relación era más usual. Así Tamarit, Pertusa, Monzón y Cervera son notificadas de la llegada de tropas tolosanas desde Andorra y es la misma villa de Puigcerdà quien hace el aviso a través de sus jurados. A raíz de estos acontecimientos se puede entender que las universidades tenían claro el grado de jerarquización al que se veían expuestas dado que eran avisadas según su rango y la gran ciudad, en este caso Lleida, ejercía de centro coordinador de las áreas de influencia del Principado.

Como se ha indicado con anterioridad, la relación de Lleida con Barcelona no fue del todo fácil debido al carácter de esta última, capital del Principat, y eje sobre el cual pivotaba cualquier decisión en torno a la elección de monarca. Barcelona, al igual que las otras capitales de la Corona de Aragón, era el punto central del cual emergían gran parte de las políticas que se llevaban a cabo por todo el país. Desde la urbe, se controlaba al resto de territorio con el fin de mantener un espacio de influencia sobre el cual construir las políticas que se llevarán a cabo y que serán representadas, a través de los estamentos, en los parlamentos y cortes. El hecho de ser capital del reino le otorga mayor peso y mayor responsabilidad, sobre todo en periodos o coyunturas contrarias al discurrir natural del tiempo. Así, en el Interregno, Barcelona no solo demuestra ser la capital del país sino que también lucha por monopolizar las decisiones de un proceso en el que el resto de ciudades y villas del reino poco o nada tendrían que aportar. A su lado estaban las instituciones que tenían sede en la misma ciudad e incluso el mismo gobernador que trabajará para que Barcelona se convierta en un foco de atracción hacia la causa de Fernando de Antequera ${ }^{56}$.

Como capital, Barcelona ejerció una influencia enorme no solo con su territorio más inmediato sino también con el resto de ciudades más o menos afines o más o menos cercanas a las políticas de la ciudad. El gran número de señorías que tenía repartidas no solo por el Principado sino también en otros reinos como en València, hizo que su papel se consolidara logrando aun mayor protagonismo en el bienio. El hecho de ser capital del territorio comporta una serie de deberes que se irán repitiendo en otras capitales que se verán más adelante como València. Barcelona, por ejemplo, ejerce de árbitro en disputas entre Manresa y Santpedor puesto que los oficiales y las autoridades municipales de la primera ciudad atacan constantemente los privilegios de Santpedor, privilegios que, por cierto, son protegidos por la capital ${ }^{57}$.

AML. Correspondència, 842, f. 181 (1411, noviembre 22).

56 Un ejemplo es el traslado que hace el gobernador, Guerau Alamany de Cervelló, de Montblanc a Barcelona como lugar de reunión del Parlamento de Catalunya hecho que no es aceptado por otras ciudades como Lleida que protestan ante la falta de rigor y la parcialidad del gobernador para con la capital (AML. Correspondència, 842 , f. $46-1411$, septiembre $26-)$.

57 Arxiu Històric Municipal de Barcelona (en adelante AHMB). Correspondència, 04/1D.XXII (sin foliar) (14101412?, julio 29). Cuando un núcleo emerge se proyecta sobre el entorno y colisiona con la capitalidad superior. En muchos casos no hace falta que la jurisdicción sea diferente. En el caso presente de Santpedor este formaba parte del inicial término extenso de Manresa y a partir del siglo XIII Santpedor ve multiplicar su población consolidando su término propio. Empiezan varias disputas con Manresa como por ejemplo, por el uso del agua 
Desde el consell de Barcelona, también se trabajará por consolidar el papel de los 12 consejeros que, de algún modo, tutorizarían cada una de las decisiones que se toman en pos de la elección de rey. Estos 12 consejeros recibían el apoyo incondicional de la urbe, pues se creía que de ellos emanaba toda autoridad al ser "elegidos" por las Cortes. Sin embargo, esto no fue apoyado por ningún municipio fuera de la influencia barcelonesa ya que consideraban una extrapolación de las capacidades de dichos consejeros y un monopolio total por parte de la capital que dejaba sin margen de maniobra a ninguna de las ciudades que formaban el Principado. Es por esto que, los jurados de Barcelona, ante la controvertida decisión de otorgar tanto poder a estos consejeros, piden al gobernador el reconocimiento público y, de este modo, paliar los constantes ataques hacia ellos ${ }^{58}$.

No obstante, no sólo existe presión por parte de la capital hacia otras ciudades y villas. Otras grandes ciudades como Girona ejercen cierta supremacía hacia otras poblaciones con el fin de mantener una amplia jurisdicción para responder a los intereses y demandas de la metrópoli que los acapara. Desde Girona, ciudad sin puerto, se intenta controlar ciertos puntos clave como son Torroella de Montgrí, sant Feliu de Guíxols o Castelló d'Empúries para tener una salida al mar y asegurarse su abastecimiento y un comercio más o menos asiduo y constante en el tiempo. No contenta con el control de estos enclaves estratégicos, desde finales del siglo XIV, hay una constante pugna con el obispo de Girona relacionada con el control jurisdiccional del reino. La ciudad pretende hacerse con ciertas poblaciones a través de la compra de las mismas con el objetivo de establecer un área jurisdiccional claramente dependiente de la urbe para convertirlas a su señoría en detrimento de la jurisdicción eclesiástica encabezada por un obispo que ahora tiene que lidiar con el consell de la ciudad por mantener el estatus de sus señorías. Con todo, el municipio no niega la importancia de la figura del obispo en los asuntos políticos del territorio. De hecho, muchas veces acude al mismo ante cualquier duda a la hora de proceder en cualquier situación que podría ser controvertida para los intereses de la urbe ${ }^{59}$.

El control de estos enclaves no sólo se ciñe a lo estrictamente territorial sino también se adscribe al plano político. Desde Barcelona se denuncia la intromisión de Girona en la designación de mensajeros por parte de Castelló d'Empúries pero los jurados de Girona no escatiman en recordar que la intervención de Barcelona en este asunto "par molt impertinent" ${ }^{\text {. }}$. No obstante, el entremetimiento en otros hechos por parte de otras instituciones también parece alarmar a los consellers. El nombramiento del baile era potestad exclusiva del monarca y así se entendió en todos los territorios de la Corona de Aragón. Sin embargo, el Batlle de sant Feliu de Guíxols, ante la previsión de una ausencia prolongada en el tiempo, decide nominar él mismo a su sustituto, lo cual contraviene la política y el designio real que ahora no cuenta con monarca. A este hecho, marcadamente complejo, se le une la actuación del gobernador el cual otorga el visto bueno para llevar a cabo la designación. La intrusión

o por la competencia en los privilegios de protección del mercado. A partir de aquí, Santpedor busca el apoyo de Barcelona y acaba siendo parte de la señoría de la capital convirtiéndose en "carrer".

58 AHMB. Llibres de Consell 02.01/1B.I-28, fol. 142 (1410, julio 12).

59 Este es el caso donde el municipio no sabe cómo actuar ante el ataque de gente de armas a los trabajadores que se encuentran reforzando la torre de la Gironella en previsión de algún inminente ataque. Una vez detenidos, el consell, pide al obispo algún consejo para actuar contra ellos puesto que "els dits malfeytors sien dats ferment e punits", Arxiu Municipal de Girona (en adelante AMGi). Correspondència, 1410-1411, fol. 89 (1411, agosto 4).

60 AMGi. Correspondència, 1410-1411, fol. 60 (1410, septiembre 15). 
en este hecho por parte de la máxima autoridad del Principado acarrea una rápida respuesta por parte de los consejeros de Girona que no duda en pautar y delimitar el papel de un gobernador que ha sobrepasado los límites de su poder, hecho que comportará otros conflictos con otras ciudades del territorio por esta extralimitación ${ }^{61}$.

Dentro del mismo municipio, las autoridades tienen que enfrentarse a los movimientos de gentes de armas que intentan desestabilizar la política con la persecución de unos intereses: el control de la municipalidad. Los bandos no tardan en manifestar su compromiso hacia uno u otro candidato reavivando conflictos que se van arrastrando desde tiempo atrás. Así, esto no solo se produce en el interior de la población sino en poblaciones cercanas donde la ocupación de castillos y pequeñas villas no deja de ser una estrategia recurrente por parte, sobre todo, del bando cercano a Jaume d'Urgell ${ }^{62}$. Dentro de las mismas murallas, la urbe no escatima esfuerzos en promover ordenanzas con respecto a su seguridad. Al igual que el resto de ciudades, no solo del Principado sino también de la Corona de Aragón, Girona emprenda una serie de medidas como el cierre de puertas, el refuerzo de las murallas y ordenanzas en relación a la prohibición expresa de llevar determinados tipos de armas dentro de las murallas de la ciudad ${ }^{63}$. El afianzamiento de las murallas obedece al miedo a una posible acción beligerante por parte de los candidatos al trono o sus valedores. Así, los jurados no dudan en hacer una llamada al refuerzo de gentes y a la consolidación de muros apelando al sentimiento de unidad en todos los reinos de la Corona de Aragón ante la amenaza de gentes armadas que se sitúan en la frontera con Castilla y con Francia ${ }^{64}$.

También otras ciudades del territorio sufrieron las consecuencias más nefastas de la violencia. En Cervera, el 25 de junio de 1411, piden ayuda al gobernador con el fin de obtener un capitán, al igual que Lleida, para cuidar y reforzar las murallas con guardia tanto durante el día como durante la noche llegando a solicitar, incluso "espies ça e llà vers les parts que sospitoses haurets" ${ }^{\circ}$. La violencia es acuciante en el término y finalmente se nombra a Guillem Ramon de Munt capitán de Cervera y de todos los núcleos de su señoría ${ }^{66}$. El detonante no llega a ser otro que la toma del castillo de Rosanes por parte de Arnau Santacoloma con la ayuda del vizconde de Castellbó aprovechando el momento de mayor inestabilidad del bienio y la presencia de tropas castellanas a las puertas de Aragón ${ }^{67}$.

$\overline{61}$ "e los dits jurats e nosaltres entenam que.l dit governador no puxa ne deia fer la dita provisió ne aquella deia ésser obeita", AMGi. Correspondència, 1410-1411, fol. 72 (1411, enero 20). En este documento se puede observar la idiosincrasia y el talante de la comunidad política de Girona haciendo frente al exceso que cometían las más altas instituciones en las competencias de sus cargos.

62 Girona no duda en ponerse en contacto con Barcelona ante la ocupación del castillo de Pals, de patrimonio real, o la ocupación de Castellví de Rosanes, que no dejan de representar más que un golpe de autoridad por parte de los bandos de esta parte del Principado (AMGi. Correspondència, 1410-1411, fol. 93 -1411, agosto 21- y 106 -1411 , diciembre 27- respectivamente).

63 AMGi. Manuals d'Acords, 1411, fol. 20v (1411, febrero 3) y 30v (1411, abril 30).

64 AMGi. Manuals d'Acords, 1411, fol. 5 (1410, diciembre 23).

65 Arxiu Comarcal de la Segarra (en adelante ACS). Correspondència, 513 (sin foliar).

66 El nombramiento de un capitán viene acompañado de una coyuntura cuya violencia es muy acuciante en el municipio. El veguer de la ciudad, nombrado por el mismo gobernador de Catalunya, se vio sobrepasado por la situación. Pese a ser el representante del monarca en la ciudad y tener que "vetllar pel compliment de les ordres $i$ manaments procedents d'instàncies superiors $i$ mantenir la pau i la seguretat pública perseguint $i$ jutjant els criminals", muchas veces, el mismo veguer, era parcial en cuanto a los bandos del municipio en el que actuaba. La sumisión a los intereses de los grupos dominantes del gobierno local y el intervencionismo municipal en los oficiales reales, dará lugar a la consolidación de los bandos, parte de ellos, apoyados y respaldados por el mismo veguer o incluso el baile (Turull, La configuración jurídica, pp. 248-266).

67 ACS. Correspondència, 513 (sin foliar) (1412, enero 11). 
El miedo recorre cada una de las villas y ciudades en las que se toman muchas decisiones en pos del fortalecimiento de la estructura de la ciudad también con el cierre de portales y el afianzamiento de murallas. Así en Lleida:

E com tot hom evidentment puxe veure lo cars sinistre en que tot lo regne és posat e sie cosa necessària que $\cdot 1 s$ murs d'aquesta ciutat sien reparats com estiguin asats en mala disposició per quals placien provehir e ordonar de que $s$ pagaran les obres fahedores en los dits murs per com que's meren a punt a fi que la ciutat sie ben guardada e que d'aquella puxen donar bon compte e rahó e nostra leyalment e fama lloable e no puxe ésser denigrada.

Acorda lo consell general que cosa necessària és per indempnitat de la ciutat que $\cdot \mathrm{ls}$ murs se reparen $a b$ gran diligència perquè delliberaren que a present sien posats per a fer les dites obres dels diners de les imposicions. Emperò que prestament sie gitada una exacció axí a lechs com a clergues e los diners que d'aquella exiran sien tornats als diners de les dites imposicions. ${ }^{68}$

Por su parte, en Puigcerdà, ordenan cerrar todos los portales, vetan las armas y obligan a recoger el grano del término ${ }^{69}$. Es tanto el recelo ante una posible situación bélica que la ordenanza de vetar armas y la compra de ellas se hace reiterativa en la urbe $^{70}$. Este hecho responde a la necesidad de los magistrados de acudir al gobernador dada la situación de la villa: la gran belicosidad de los bandos y su situación, cerca de la frontera, determinan las pautas de actuación de la urbe ${ }^{71}$. No obstante, otro hecho que preocupa a la universitas es la pérdida de autonomía a favor de Perpiñán, capital preeminente en la zona norte la cual no reconoce a la urbe como un territorio independiente sino como una villa más de sus posesiones ${ }^{72}$. La pérdida de autonomía de Puigcerdà hace acudir a sus representantes de forma continua al gobernador sobre todo cuando la intromisión de altos oficiales venidos desde Perpiñán altera la justicia ordinaria y, por tanto, la estabilidad del municipio y La Cerdanya ${ }^{73}$.

\section{El Reino de València y la violencia de sus bandos}

València, capital del reino, acoge en su interior numerosos problemas en relación con las banderías. En el caso de la ciudad, la forma de actuar no difiere mucho del resto de ciudades o entidades menores. Empero, lo que determina su actuación es el hecho de erigirse como capital de un reino y sostener políticamente al resto de ciudades amparándose en un rol estrictamente económico y, más aún si cabe, paternal.

AML. Consell General, 405bis, f. 8 (1410, junio 3).

69 Arxiu Comarcal de la Cerdanya (en adelante ACC). ACCE130-125-Ajuntament de Puigcerdà, f. 45 (1410, junio 6).

70 ACC. ACCE130-125-Ajuntament de Puigcerdà, f. 47 (1410, julio 21); f.48 (1410, agosto 20).

ACC. ACCE130-125-Ajuntament de Puigcerdà, f. 55v (1411, febrero 20).

ACC. ACCE130-125-Ajuntament de Puigcerdà, f. 68 (1411, septiembre 29).

73 Sabaté, "Perpinyà, capital baixmedieval", p. 184 y 195. Tanto el condado de Rosselló como el de Cerdanya son la expresión más inmediata del radio de influencia de la ciudad de Perpiñán que ha buscado durante el siglo XIV y XV el escenario donde hacer tangible su prosperidad económica y su fuerza política estructurando estos territorios a las demandas del momento. 
El municipio se presenta como un núcleo que vertebra la totalidad del territorio del reino y al cual hace dependiente ${ }^{74}$. Al frente de la urbe, están las oligarquías, las cuales tienen la certeza de ser garantes de la representatividad no solo de forma oficial de su universidad sino también de gran parte del territorio valenciano. Todo ello va ligado al honor y prestigio ya que "con la capitanía, había que implicar la superioridad indiscutible en todos los ámbitos de las administraciones civil y eclesiástica" 75 .

El ser capital del reino implicaba también la aceptación de diversas cargas y obligaciones mayores e, incluso, más graves que las que pesaban sobre el resto de entidades poblacionales. Entre esas cargas se encontraban los bandos. A principios del siglo XV la nobleza valenciana tiene que hacer frente a un nuevo periodo donde se ve en entredicho su papel preeminente frente al resto de actores políticos y económicos. Ahora, con la llegada de nuevos tiempos se enfrentan a un clima con "velles lleis i privilegis aconseguits fonamentalment durant el període comprès entre la conquista [1238] i les guerres de la Unió [1347-1348]" "76. Otro factor que va a marcar el papel de la ciudad frente al conflicto es la "sobreabundancia" de nobles en la misma ciudad. Al ser capital del reino y radio económico del mismo, la instalación de grandes linajes desde la toma del municipio hasta el mismo siglo XV, determina las relaciones no solo con el monarca sino también con los jurados de la ciudad con los que se enfrentó en luchas intestinas por el dominio del mismo municipio y de otras instituciones. Las banderías de la capital fueron encabezadas por los bandos de Vilaragut (urgelista) y Centelles (fernandino) los cuales no solo se enfrentaron dentro de las murallas de la urbe sino también a lo largo y ancho de todo el reino.

La correspondencia entre València y el resto de municipios, políticos o entidades políticas en este periodo es diaria. La violencia y reyertas tanto dentro de los muros como en su exterior hicieron temer los peores presagios a los jurados de la ciudad. El recelo de no garantizar la estabilidad en el municipio, la subversión de otras entidades políticas dependientes o no de la urbe y los avisos constantes de tropas extranjeras hacen que sean frecuentes las convocatorias a host $i$ cavalcada en la ciudad y los lugares de su contribución ${ }^{77}$. A ella se adherían los vecinos de las distintas villas y grandes nobles, ciudadanos y patricios de València, como es el caso de Felip Boïl, Berenguer de Vilaragut, Eximén Perez de Calatayud y Galvany de Villena, todos ellos hombres fuertes convocados por los jurados ${ }^{78}$. La convocatoria de host i cavalcada no deja de ser el último recurso al cual acudir. Sin embargo, una vez convocada, podría darse el caso de que alguna de las ciudades fuera rebelde. Cuando el gobernador del reino, Arnau Guillem de Bellera, decidió convocar las huestes de Morella por un lado y la de sus aldeas por otro, incurrió en un contrafuero

74 La organización de la ciudad y la vertebración del resto del territorio se hacen a través de una atribución metafórica de rasgos orgánicos a las formas y expresiones sociales. Este hecho no resulta nuevo puesto que es algo recogido por muchos pensadores y filósofos a lo largo del medievo y cuyo origen se remonta al Corpus Mysticum de san Pablo. La tradición del Corpus Mysticum es recogida por autores como santo Tomás de Aquino y aplicada a muchas teorías políticas de autores coetáneos como Francesc Eiximenis. Cabe señalar que la teoría del Corpus Mysticum pasará a ser conocida como Corpus Politicum en la Edad Media, momento en el que se tiene más presente esta organización corporativa de la Sociedad.

75 Rubio, "Valencia: la conciencia de capitalidad", p. 232. Tal como señala Rubio Vela, la capitalidad también iba ligada a unes prerrogativas "cuya defensa suponía también la de los propios jurats como autoridad judicial de todo el reino".

76 López Rodríguez, “Aristocràcia i orígens”, p. 160.

77 La Particular Contribución de València era el territorio más inmediato que rodeaba la ciudad; sobre este, la ciudad poseía jurisdicción administrativa, judicial y fiscal.

78 Arxiu Municipal de València (en adelante AMV). g³-10 Lletres Missives, ff. 45-45v. 
puesto que, tal y como indicaron los jurados, "Morella ha acostumat traure sa ost a les aldees ab ella ensemps sots la bandera de la dita vila e sots lo justícia e jurisdicció de la dita vila"79. No es de extrañar el deseo del gobernador de convocar a las aldeas por un lado, fieles a la opinión del gobernador (urgelista), ya que Morella ejerció de capital trastamarista y estaba en constante conflicto con estas por la jurisdicción y por temas económicos ${ }^{80}$.

La seguridad es lo principal ante cualquier ataque eventual. Las primeras disposiciones del Consell tienen relación con la protección de la urbe: se cierran portales, se otorga jurisdicción para hacer llamada a host $i$ cavalcada, se arma soldados de vigía para los portales que quedan abiertos tanto para el día como para la noche y se prohíbe la entrada de armas ${ }^{81}$. No solo lo hace en su metrópoli sino también en los territorios que están bajo su contribución como son Alpuente, El Puig y Penàguila a los que, en 1411, les son enviadas dos bombardas a cada uno de ellos ${ }^{82}$. El peligro era constante $\mathrm{y}$, por ello, la ciudad les sugiere que se refuercen ante el mismo. Una vez fortalecidas y en caso de inicio de cualquier invasión o conflicto, el municipio actuará en defensa de otros y de él mismo ${ }^{83}$. El peligro no solo venía de dentro sino también del exterior y, sobre todo, de la frontera. Son constantes los avisos de la presencia de tropas, sobre todo tropas castellanas, a las puertas del reino ${ }^{84}$. En alguna ocasión, València se ve involucrada de una forma directa, como la de los ataques sufridos por el maestre de Montesa en su castillo de Vilafamés y al cual le pide que se ponga en contacto con otras villas reales para reforzarse y con el gobernador para

79 AMV. $\mathrm{g}^{3}-10$ Lletres Missives, f. 34v (1410, agosto 9).

80 Las aldeas de Morella deseaban la independencia y aprovecharon el Interregno para alzarse y conseguirla. Las aldeas que lucharon contra Morella fueron Cinctorres y Forcall seguidas de Vilafranca, el Portell, Castellfort y Vallibona. El método que utilizaron para desentenderse de la jurisdicción morellana fue el del asedio, no dejando entrar víveres ni salir personas. Desde València se apoyó este movimiento ya que Joan de Vilaragut, cabeza del bando Vilaragut y urgelista, ayudó con la llegada de dos compañías de armas (Miralles, "Guerra civil en termes de Morella", p. 78).

81 AMV. Manuals de Consells, A-24, f. 242 (1410, junio 5). Las órdenes al respecto de tener en guarda la ciudad se acrecientan con el paso del tiempo y con la sucesión de acontecimientos de rebeldía y manifestaciones violentas dentro de la ciudad y otros municipios. Así, el 25 de abril de 1411, la ciudad hace disponer nuevas ordenaciones donde se aumenta la guardia y control (AMV. Manuals de Consells, A-24, f. 348) y estas son reiteradas pocos meses después, el 11 de agosto de 1411 (AMV. Manuals de Consells, A-24, f. 381).

82 AMV. Manuals de Consells, A-24, f. 396 (1411, septiembre 9); f. 412 (1411, octubre 30).

83 Así lo hace con Alacant y Orihuela donde esta última, además, era protegida por la figura de su gobernador Olfo de Perexida, y ejercía cierta tutela con Alacant ya que, a través de València, Orihuela se encargaba de reforzar y abastecer de alimentos y guardias el Castillo de Alacant (AMV. $\mathrm{g}^{3}-10$ Lletres Missives, f. 19 (1410, junio 21); f. 31 (1410, julio 26). Esto también ocurre con Castelló de la Plana, donde la misma capital otorga 150 libras para que sea reforzada (AMV. $\mathrm{g}^{3}-10$ Lletres Missives, f. 162v, 1411, octubre 16). La conflictividad en Castelló, pasaba por la exhibición de armas que podían constituir el enfrentamiento a través de la provocación. La ciudad, el 28 de septiembre de 1410, se rebela ante el gobernador, por lo que la capital, València, tiene que convocar la host $i$ cavalcada y ordena lo mismo para Morvedre, quien tiene que acompañar también al gobernador con el pendón del municipio y sus oficios reiterando su sumisión (AMV. Manuals de Consells, A-24, f. 291). Un año después, el 11 de noviembre de 1411, envían 200 ballesteros a la ciudad y a Villareal (AMV. Manuals de Consells, A-24, f. 416v). Para más información sobre Castelló: Viciano, "Violencia y sociedad en una villa medieval"; El derrocamiento de casas adosadas a la muralla viene siendo común en la capital conforme avanza el tiempo no solo para el afianzamiento de la urbe sino para evitar la acogida de gente de armas en el interior de estos albergues (AMV. $\mathrm{g}^{3}$-10 Lletres Missives, f. 165, 1411, octubre 27).

84 Alfons el Vell, duque de Gandia y candidato al trono, le es anunciada la presencia de 500 lanceros en la frontera con Murcia capitaneados por Pero Manríquez. La ciudad avisa también a otras ciudades del peligro de estas huestes, ciudades muy próximas a la frontera. En muchas ocasiones, el posicionamiento en la frontera se realiza como elemento de presión, en este caso ejercido por Fernando de Antequera para hacer valer sus intereses (AMV. $\mathrm{g}^{3}-10$ Lletres Missives, f. 80. Se avisa a los jurados de Xàtiva, Ademuz, Castellfabib y Alpuente el mismo día de la llegada de las noticias -1410, noviembre 20) Otras veces, sin embargo, estas huestes materializan sus ataques y someten a muchas poblaciones con asedios a las fortalezas de las mismas. 
que asedie a los atacantes ${ }^{85}$. Los peligros, también, vienen de mar adentro, donde galeotas de genoveses, piratas y musulmanes hacen y deshacen barcas llenas de suministro y mercaderías ${ }^{86}$.

La pacificación de otras ciudades del reino fue clave para mantener al reino en paz. En Xàtiva, los jurados llegan a perder el control tras la llegada del bando Centelles:

lo Castell de Xàtiva és en un punt molt perillós per tat com alguns nobles e cavallers e hòmens de paratge ab singulars de la dita ciutat qui són de lur vot e mala opinió hi ha fets e fan terribles coses e novetats d'occupar-les en tant que volen mostrar a lur ordenança e manament la dita ciutat ${ }^{87}$

Ante esta situación, el gobernador acude a poner orden en la ciudad acompañado de hombres con armas pero no es bien recibido y, ni tan siquiera, puede entrar al municipio. Ante el escándalo, los jurados de València piden a los de Xàtiva pacificar la ciudad: "siats sol·lícitis e ab sobirana vigilancia guardets aquexa ciutat al senyor rey e feelment li lunyets sinistres e comunió de persones adversants" $"$. Lo mismo sucede con Borriana. Villa estratégica cerca de la ciudad de Castelló y no lejos de Morvedre y València, acoge a hombres armados del bando castellano que tomarán después Castelló y Vila-real ${ }^{89}$. Esto hace tomar medidas a los jurados valencianos, informando de la ilegalidad que están cometiendo en detrimento de la estabilidad del reino y reforzando la vigilancia en el camino de Morvedre a la altura de Puçol, camino de entrada por el norte a la capital ${ }^{90}$.

Las noticias de banderías por parte de castellanos rápidamente se expanden por todo el reino. Llegan informaciones de todas las partes en las que muchas poblaciones, la mayoría tomadas por la parcialidad que apoya a Fernando de Antequera, acogen a estos hombres de $\operatorname{armas}^{91}$. Sin embargo, no solo son los hombres castellanos los que empiezan a posicionarse. Desde el bando del d'Urgell también toman ciudades como Cabanes, cerca de Castelló gracias al apoyo de tropas gasconas ${ }^{92}$. Ante la alarma constante y el clima posbélico (después de la batalla de Codolar del 27 de febrero de 1412) los jurados recurren a la mediación de Vicente Ferrer con el fin de apaciguar los ánimos entre los bandos. La predicación pública y sus sermones podrían evitar un nuevo conflicto. Es por esto que envían una carta a los nueve compromisarios reunidos en Caspe (él era uno de ellos) para hacerle venir e intentar firmar la concordia entre bandos ${ }^{93}$.

85 AMV. $\mathrm{g}^{3}-10$ Lletres Missives, f. 93v (1411, enero 6). Finalmente, el gobernador no pudo tomar el castillo hasta dos meses más tarde, el 10 de marzo de 1411 (AMV. g⿳3 10 Lletres Missives, f. 115v).

86 Los avisos se dan desde València a ciudades como Cullera, Morvedre (Sagunto), Tortosa e Ibiza (AMV. $\mathrm{g}^{3}-10$ Lletres Missives, f. 123-127).

87 AMV. $\mathrm{g}^{3}-10$ Lletres Missives, f. 138 (1411, julio 9).

88 AMV. $g^{3}-10$ Lletres Missives, f. 150 (1411, agosto 21). El pavor de no mantener en unión a las principales ciudades del reino hace intermediar a la capital en este tipo de desavenencias y lucha de bandos. Lo que pretende València es mantener en orden el patrimonio real para la llegada del nuevo soberano.

89 AMV. $\mathrm{g}^{3}-10$ Lletres Missives, f. 180 (1411, diciembre 12).

90 AMV. $\mathrm{g}^{3}-10$ Lletres Missives, f. 186v (1411, diciembre 31).

91 El Consell envía una carta a Benaguassil pidiendo explicaciones y respuestas al hecho de acoger a esta gente de armas los cuales han dañado y robado junto a habitantes del municipio (AMV. $\mathrm{g}^{3}-10$ Lletres Missives, f.194, 1412, enero 11).

92 Por otro lado, envían otra carta a los jurados de Cabanes, cerca de Vilafamés y del territorio del maestre de Montesa, Romeu de Corbera, por acoger a gascones (AMV. g³-11 Lletres Missives, f. 5. 1412, marzo 23).

93 AMV. $\mathrm{g}^{3}-11$ Lletres Missives, f.41 (1412, junio 23); f.43 (1412, junio 25). Dos años antes, con la muerte del 
Mientras, en Alzira, núcleo de especial importancia por su tamaño y por encontrarse a caballo entre Xàtiva y València, la muerte del rey hace cerrar la ciudad ante cualquier atisbo de entrada de prohombres extranjeros y refuerzan sus portales con una mayor vigilancia ${ }^{94}$. Días después de conocer la noticia, el bando de los Centelles intenta entrar en la ciudad aunque su paso fue impedido, ya que "sens licencia del governador no parlan ab lo consell per revocar en corriment de les penes"95. Así, con el cierre de puertas se evitaría la entrada de personas que podrían poner en peligro la seguridad de la ciudad ${ }^{96}$.

Un año más, tarde la urbe, ante el permanente estado de emergencia y la pujante tensión vivida en el resto del reino, ordena el cierre total de los portales y la construcción de bombardas a la vez que se arman a hombres y se pide a las viudas que compren armas y recojan los víveres del término para guardarlos dentro de la villa ${ }^{97}$. $\mathrm{Y}$ es que el problema de avituallamiento sacude la ciudad. València se erige como centro de almacenamiento y recepción de grano del reino con el objetivo de poner fin al posible desabastecimiento de la capital sin importar la situación de aquellos municipios que están obligados a donar parte de su cosecha a la urbe. En Alzira, se ve reflejado a partir de 1412, cuando por dificultades económicas y la destrucción de cosechas cargan 15.000 sueldos en censales para la compra de grano y prohíben la salida del mismo del término municipal ${ }^{98}$.

Otra de las ciudades importantes del reino, Castelló, también experimenta el temor hacia una posible guerra derivada de la extrema conflictividad que vive el reino. La ciudad no duda en hacer énfasis en el refuerzo tanto de sus murallas como de sus portales. Estas murallas y portales eran constantemente vigilados tanto por el día como por la noche y a cada "guaita" le era pagada una cantidad determinada de sueldos. Estos vigilantes debían "anar ab ses armes e se’n porte pa, vi e ço que haurà mester e que ningú no se'n gos partir del maytí tro al vespres e aço sots pena de $V$ sous de València" ya que la sedición era pagada, como se especifica, en una multa pecuniaria $^{99}$. No resulta novedoso que fueran los mismos vigilantes los que aportaran sus armas debido a la escasez de la misma dentro de la urbe y a la falta de contingentes entre su población ${ }^{100}$. De hecho, la misma ciudad pide a sus habitantes, pese a la lógica que siguen otras ciudades para evitar conflictos, que posean armas tanto en el interior del municipio como también en la misma plana y heredades.

Pero, las políticas restrictivas no se harán esperar. El cierre de algunos portales comporta el descontento de algunos de sus habitantes puesto que esto no permitiría la entrada de trigo a la ciudad y, por tanto, no podrían abastecerse $\mathrm{e}^{101}$. El abasteci-

rey Martín, la ciudad prepara todo lo necesario para la primera predicación del dominico (AMV, Manuals de Consells, A-24, f. 245v, 1410, junio 13).

94 Arxiu Municipal d'Alzira (en adelante AMA), Consells Municipals, 12, f. 9 (1410, junio 3).

95 AMA. Consells Municipals, 12, f. 15v (1410, junio 21).

96 Más tarde, el conde de Dénia, Alfons el Vell, candidato también al trono, intenta entrar a la villa a través de una barca por el río aunque fue rechazado rápidamente (AMA. Consells Municipals, 12, f.36v).

97 AMA. Consells Municipals, 13, f. 6 (1411, junio 8); f.31 (1411, septiembre 6).

98 AMA. Consells Municipals, 13, f. 81 (1412, enero 23); sobre la destrucción de cosechas f. 83 (1412, febrero 2). Sobre la prohibición de exportar grano AMA. Consells Municipals, 14, f. 17 (sin fecha).

99 Arxiu Municipal de Castelló (en adelante AMC). Actes Capitulars, 1411-1412, fol. 6v (1411, junio 29).

100 Un ejemplo de ello es que los jurados de la ciudad piden que llegue a la ciudad un cuirater para realizar 50 corazas, así como un ballestero para que fabrique otras 50 ballestas para armar a la población (AMC. Actes Capitulars, 1411-1412, fol. 6 -1411, junio 23).

101 AMC. Actes Capitulars, 1411-1412, fol. 4 (1411, junio 11). Los vecinos de la parroquia de san Nicolás emiten sus quejas a los jurados de la ciudad porque con el cierre de la puerta de Pemar no permite la entrada de grano 
miento es un tema que preocupa, y mucho, a los jurados de la ciudad, los cuales no dudan en prohibir la salida de vituallas sin el permiso de los mismos ${ }^{102}$. Asimismo, también prohíben la salida de los habitantes bajo la pena de 20 morabatines de oro ya que el temor a la despoblación o el miedo de los jurados hacia una posible ayuda no solo a los bandos sino también a los contingentes que estaban de paso por la ciudad, podría comportar un aumento de la inestabilidad de la urbe ${ }^{103}$. Y es que, Castelló, se convirtió en lugar de paso de las huestes del gobernador de València que se dirigieron hacia el norte y es una ciudad próxima a los dominios del maestre de Montesa y a los parlamentos que se celebraron tanto en Vinaròs como en Traiguera.

\section{El interregno en Aragón: los casos de Zaragoza y Teruel}

Las ciudades de Aragón son puntos indispensables para entender el proceso de elección del monarca y, sobre todo, para entender el compromiso al cual se llegó en Caspe en 1412. Desde su capital, Zaragoza, emanan los edictos más importantes y, al igual que Barcelona o València, tienen sede las instituciones más importantes del reino. Las desavenencias entre las grandes familias potentadas de la ciudad así como la conflictividad, que había marcado parte del siglo XIV y principios del siglo XV, determinan la posición de esta ante el candidato: las facciones encabezadas por el arzobispo, García Fernández de Heredia y el gobernador, Gil Ruiz de Lihorí eran claras partidarias de la causa castellana, al contrario que sus adversarios, los Luna. De este modo, se observa cómo la ciudad, por el mero hecho de constituirse capital de Aragón, vive en su seno las disputas más extremas del periodo, dando lugar a la enemistad o antipatía de otras urbes como son Huesca o Albarracín.

El temor a la guerra estaba presente en cada uno de los rincones del territorio y fe de ello son las ordenanzas que los jurados de la ciudad aplican a su universidad. Así, por ejemplo, se observa, que desde la ciudad:

no puedan entrar ni entren en aquella por via de occupar la dita ciudat o mover scandalo o bolicio en aquella ni en otra manera si no es con licencia e voluntat de los ditos senyores e por expellir, contrastar e fuera gitar aquellos que en la dita ciudat no entren ni sian $(. . .)^{104}$.

Zaragoza observa también que el vacío que podía dejar alguno de los miembros de las más importantes instituciones, podía suponer un revés para la estabilidad no solo de la ciudad sino también del mismo reino. Así, ante la ausencia del gobernador, que acude a Calatayud para reunirse en el parlamento, se propone alargar a Blasco Fernández de Heredia, su lugarteniente, la jurisdicción civil y criminal. De este modo, Blasco Fernández de Heredia actuaría como gobernador durante un corto periodo de tiempo con el beneplácito de los jurados de la capital "atendidas las grandes bandosidades e voluntades contrarias que son en el dito regno"105.

a la ciudad.

102 AMC. Actes Capitulars, 1411-1412, fol. 32 (1412, marzo 16).

103 AMC. Actes Capitulars, 1411-1412, fol. 5 (1411, junio 11).

104 Villanueva, “Teruel en tiempos del Interregno...”, p. 897. Véase también: Archivo Municipal de Zaragoza, (en adelante AMZ) Libro de Pregones o Cridas 1, Cuadernillo 14, f. 37v-38v (1410, julio 13).

105 Ibidem, p. 897. Véase también: AMZ. Libro de Pregones o Cridas 1, Cuadernillo 14, f. 75v-77 (1411, marzo 
Por lo que respecta a Teruel, la división interna de los bandos anunciaba un periodo claramente conflictivo donde el temor a la guerra también sacude la política municipal. Pero esto no solo sucedió dentro de las murallas de la ciudad sino también en las aldeas que formaban parte de su Comunidad. Así

Lidón, Argente, Rillo, Allepuz, Hinojosa, Villalba Baja, Mezquita de Jarque, Cuevas de Almudén, Jarque de la Val y Camarillas tuvieron que endeudarse por la compra de armas con las que defenderse en las guerras durante el período en que no hubo monarca ${ }^{106}$.

De este modo, se puede ver que gran parte del dispendio realizado desde las instituciones municipales van a parar a la salvaguarda y vigilancia de Teruel y sus aldeas ${ }^{107}$. Los libros que aparecen en el archivo constatan que la preocupación era máxima y los jurados no dudan en invertir cualquier cantidad a la protección de las poblaciones. Un ejemplo es el del pago al refuerzo de murallas el cual evidencia, por un lado, la elevada cantidad invertida y, por otro, que esta cantidad irá pagándose progresivamente hasta el año 1413 debido a las dificultades económicas que pasaba no solo la urbe sino sus aldeas:

considerado que era e es gran necessidat que las obras a [...] e muros de la dita ciudat (...) se continuasen a obrar sobre lo qual habida concordia con los regidores de las aldeas de la dita rudu que por mil que las obras no cessassen, fuesen amancipados tres mil solidos jaqueses que por la dita ciudat pagar se debían a las ditas obras del anyo millessimo CCCC XIII próximo viniente ${ }^{108}$.

Otro de los problemas importantes a los que se enfrenta Teruel es Villel. Las reuniones del consejo de la ciudad muestran unos gastos continuos en cabalgadas hacia la villa sublevada ${ }^{109}$. El porqué de esta sublevación viene marcado por el hecho de las políticas llevadas a cabo por su señor, Juan Fernández de Heredia, sobrino del arzobispo de Zaragoza que, tras su muerte, decidió vengar a estas villas en dominio claramente urgelista. Y es que el hermano del castellán de Amposta, uno de las cabezas más visibles del urgelismo, había tomado el castillo de Albarracín. A ello se le une la heredada enemistad entre las aldeas y la ciudad: si la ciudad estaba influenciada por los partidarios del de Trastámara, las aldeas, dada esta rivalidad, se posicionarán en torno a Jaume d'Urgell. De este modo:

\section{9).}

106 Ibidem, p. 899.

107 Todas las villas aspiraban a obtener el rango de ciudad. Se trata de un rango honorífico concedido por la monarquía y demandado por el propio municipio. No es más que "el techo simbólico más alto que aspiraban a llegar el conjunto de villas y aldeas". De ahí el nacimiento de estos conflictos entre villas y ciudades que se repiten en todos los territorios de la Corona de Aragón como se ha visto, también, entre Morella y sus aldeas (Navarro, "Ciudades y villas del reino de Aragón", p. 210").

108 Archivo Histórico Provincial de Teruel (en adelante AHPT). Manual de Actos del Concejo, caja 8, doc. 22, f. 7 (1411, mayo 5).

109 "La ciudad no escatimó gastos, ya que la estimación de lo invertido por el concejo turolense en todos estos asuntos durante año y medio ascendía a más de 18.000 sueldos jaqueses (casi 12.000 en el año 1412); un importe nada desdeñable en el contexto del erario municipal si consideramos que el presupuesto anual rondaría los 30/35.000 sueldos (lo que supone entre 35-40\% del presupuesto)" (Villanueva, "Teruel en tiempos del Interregno...," p. 901). 
la ofensiva debió organizarse contra Villel, Libros, Tramacastiel, Cascante y otros lugares en los años que siguieron a la muerte de Martín I, período en el que se incrementan considerablemente las discordias y conflictos entre la ciudad y la comunidad de aldeas ${ }^{110}$.

Finalmente, parte de los habitantes de Villel, así como de otras villas como Tramacastiel, quedaron presos, puesto que la fuerza y el soporte económico para evitar estos alzamientos fue mucho mayor y porque la mayor parte de Aragón (y de la misma Corona) ya había decidido dar su apoyo a la causa de Fernando de Trastámara ${ }^{111}$.

Teruel, al igual que el resto de centros neurálgicos de la Corona de Aragón, se enfrenta a una doble problemática. Por un lado, como capital, existe un conflicto perenne desde finales del siglo XIV con sus aldeas por los derechos de justicia civil y criminal. El conflicto, a priori, es más bien en término jurisdiccional, aunque, en un periodo como este, la violencia se vuelve más acuciante si a ello se le suma la eterna rivalidad entre las familias turolenses de los Marcilla y Muñoz. Todo esto no es sino el reflejo de lo que ocurre en los grandes centros rectores de la Corona de Aragón y los bandos turolenses no son menos. Se trata de que:

los bandos locales de una u otra ciudad no son sino peones de intereses de gentes de más alta condición. Esto formaba parte importante de la política de acercamiento de los hombres claves del reino que fue desarrollada hábilmente por el nuevo soberano $^{112}$.

\section{Conclusiones}

La independencia de los municipios ganada progresivamente desde el siglo XIV y la posición más que debilitada del rey durante esta coyuntura, confluyen en un contexto excepcional: el Interregno. La asunción de nuevas corrientes de pensamiento y la instauración del derecho romano desde el siglo XII permite a las ciudades llevar a cabo una serie de políticas que tendrán como resultado el control de una situación que, lejos de esa autonomía asumida gracias a una serie de prerrogativas, podría haber desembocado un bienio donde la política hubiese sido marcadamente anárquica.

En el Interregno se hacen aún más visibles los episodios de violencia urbana donde los grupos oligárquicos encuentran su forma de ser. Estas élites, que controlan el acceso y los métodos de acceso al grupo dominante harán por mantenerse en un equilibrio constante $\mathrm{o}$, en este caso, intentar hacerse con las riendas de un poder en el que el rey ahora no puede interferir. El papel de las universidades se centra tanto en el hecho de dirimir y pronunciarse ante el conflicto como en intentar mantener la paz interna dentro de sus propios pobladores. Gracias a eso, los municipios adquieren un papel muy importante en cuanto a su autonomía y en cuanto a la gestión del proceso no sin hacer frente, desde las mismas instituciones e imbricadas en ellas, a las banderías que azotan cada uno de los reinos. Es por eso que la violencia responde a la

\footnotetext{
$110 \quad$ Ibidem, p. 900.

111 AHPT. Manual de Actos del Concejo, caja 8, doc. 22, f. 28v (1411, octubre 19). Domingo Muñoz, vecino de Teruel, recibe 286 sueldos para el pago de 4 ballesteros y 6 lanceros que iban a su compañía para la defensa de Domingo Gil en Tramacastiel y la custodia de los presos en Villel.

112 Ibidem, p. 908.
} 
conjunción de intereses de los diferentes agentes sociales que integran los diferentes estamentos. Desde las magistraturas luchan por la consecución de la paz porque, el establecimiento de un verdadero orden público, permitirá que prospere no sólo la decisión crucial de elección de nuevo monarca sino el desarrollo económico que se viene experimentado desde principios de siglo.

\section{Bibliografía}

Barraqué, Jean-Pierre, "Construire une identité de capitale. Saragosse à la fin du Moyen Âge", Ante su identidad: la Ciudad hispánica en la Baja Edad Media, ed. José Antonio Jara Fuente, Cuenca, 2013.

Barraqué, Jean-Pierre, "Les idées politiques de Francesc Eiximenis", Le Moyen Âge, revue d'histoire et philologie, 3/114 (2008), pp. 531-556.

Barrio Barrio, Juan Antonio, "Que als dits ordenaments e capitols sien meses en memòria de scriptura. Modelos de identidad urbana en el reino de Valencia siglos XIII-XV', Anales de la Universidad de Alicante. Historia medieval, 16 (20092010), pp. 245-274.

Belenguer Cebrià, Ernest, El com i el perquè del Compromís de Casp (1412), història i debat, Barcelona, 2012.

Bellveser, Ricard, Els valencians en el Compromís de Casp i en el Cisma d'Occident, València, 2013.

Black, Anthony, El pensamiento politico en Europa: 1250-1450, Cambridge, 2003.

Cawsey, Suzanne, Reialesa i propaganda: l'eloqüència reial i la Corona d'Aragó (1200-1450), València, 2008.

Francisco Olmos, José María De, “Jaime II y la 'Constitución' de la Corona de Aragón”, Anales de la Universidad de Alicante. Historia medieval, 11 (1996-1997), pp. 521-530.

Furió i Diego, Antoni, “El Compromís de Casp a través de la història”, Martí l'Humà darrer rei de la dinastia de Barcelona, ed. Teresa Ferrer i Mallol, Barcelona, 2015, pp. 815-865.

— "Un debat inacabat. El Compromís de Casp a través de la història", Martí l'Humà darrer rei de la dinastia de Barcelona, ed. Teresa Ferrer i Mallol, Barcelona, 2015, pp. 815-865.

Guinot Rodríguez, Enric, "Sobre la gestió del patrimoni reial de la Corona d'Aragó en temps del rei Martí l'Humà", Martí l'Humà darrer rei de la dinastia de Barcelona, ed. Teresa Ferrer i Mallol, Barcelona, 2015, pp. 273-284.

Iradiel Murugarren, Paulino, "Señoríos jurisdiccionales y poderes públicos a finales de la Edad Media", Poderes públicos en la Europa medieval: principados, reinos y corones, Estella, 1996, pp. 69-116.

— "Formas del poder y de organización de la sociedad en las ciudades castellanas de la Baja Edad Media", Estructuras y formas del poder en la historia, Salamanca, 1991, pp. 23-50.

Juncosa Bonet, Eduard, "Pensar el pacto en la Corona de Aragón", Avant le contrat social... Le contrat politique dans l'Occident médiéval (XIIIe-XVe siècle), París, 2011, pp. 451-480. 
— "Muyren los traydors!" La lucha de bandos en Tarragona a fines del siglo XIV", Hispania. Revista española de Historia, 75/250 (2015), pp. 441-466.

Ladero Quesada, Miguel Ángel, "Poderes públicos en la Europa medieval: principados, reinos y coronas", Poderes públicos en la Europa medieval: principados, reinos y corones, Estella, 1996, pp. 19-68.

Leccupre-Desjardin, Élodie, Bruaene, Anne, De Bono Communi. The Discourse and Practice of the Common Good in the European City (13th-16th c.), Turnhout, 2010.

López Rodríguez, Carlos, "Aristocràcia i orígens de l'Estat Modern: el poder polític de la noblesa del Regne de València (1410-1446)", Butlletí de la Societat Catalana d'Estudis Històrics, 13 (2002), pp. 159-176.

Mackay, Angus, "La conflictividad social urbana", Actas del VI coloquio internacional de historia medieval de Andalucía: las ciudades andaluzas, siglos XIII-XVI (Estepona, 1990), Málaga, 1991, pp. 509-524.

Mestre i Godes, Jesús, El compromís de Casp: un moment decisiu en la història de Catalunya, Barcelona, 1999.

Miralles Sales, Josep, "Guerra civil en termes de Morella a la mort del rei Martí (1411-1412)", Boletín de la Sociedad Castellonense de Cultura, 47 (1971), pp. 77-86.

Naegle, Gisela, "Armes à double tranchant? Bien Commun et Chose Publique dans les villes françaises au Moyen Âge", De Bono Communi. The Discourse and Practice of the Common Good in the European City (13th-16th c.), Turnhout, 2010, pp. 55-70.

Narbona Vizcaíno, Rafael, "Gobierno político y luchas sociales: patricios y malhechores siglos XIV y XV", Saitabi: revista de la Facultat de Geografia i Història, 39 (1989), pp. 81-98.

- "La idiosincrasia de las sociedades urbanas en la Coronoa de Aragón: ideales, realidades políticas y representación social (siglos XIII-XV)", El poder a l'Edat Mitjana, Lleida, 2003, pp. 293-322.

- "Algunas reflexiones sobre la participación vecinal en el gobierno de las ciudades de la Corona de Aragón (ss. XII-XV)", Res Publica, 17 (2007), pp. 113-150.

— "Ideología y representación cívica en la Sociedad hispánica medieval", El món urbà a la Corona d'Aragó del 1137 als decrets de Nova Planta: XVII Congrés d'Història de la Corona d'Aragó = Congreso de Historia de la Corona de Aragón, Barcelona, 2003, pp. 273-288.

- "Cultura política y comunidad urbana: Valencia, siglos XIV-XV", Edad Media: Revista de historia, 14 (2013), pp. 171-211.

Navarro Espinach, Germán, "Ciudades y villas del reino de Aragón en el s. XV. Proyección institucional e ideología burguesa", Anales de la Universidad de Alicante. Historia medieval, 16 (2009-2010), pp. 195-221.

Nieto Soria, José Manuel, "Propaganda política y poder real en la Castilla Trastámara: una perspectiva de análisis", Anuario de estudios medievales, 25/2 (1995), pp. 489-516.

Prevenier, Walter, "Utilitas communis in the low countries (thirteenth-fifteenth centuries): from social mobilisation to legitimation of power", De Bono Communi. The Discourse and Practice of the Common Good in the European City (13th16th c.), Turnhout, 2010, pp. 205-216.

Rubio Vela, Agustín, "Valencia: la conciencia de capitalidad y su expresión retórica en la prosa municipal cuatrocentista", Anales de la Universidad de Alicante. Historia Medieval, 13 (2000-2002), pp. 6-63. 
Sabaté i Curull, Flocel, "Regnat de Martí I: el govern del territori i els bàndols", Martí l'Humà darrer rei de la dinastia de Barcelona, ed. Teresa Ferrer i Mallol, Barcelona, 2015, pp. 69-119.

— "Per què hi va haver un Compromís de Casp?", Els valencians en el Compromís de Casp i en el Cisma d'Occident, ed. Ricard Bellveser, València, 2013, pp. 45110.

— "Identitat i representativitat social a la Catalunya baixmedieval", El Compromís de Casp, negociació o imposició?, ed. Àngel Casals, Barcelona, 2013, pp. 53-94.

— "Estamentos, soberanía y modelo político en la Cataluña Bajomedieval", Aragón en la Edad Media, 21 (2009), pp. 245-278.

— "El Compromiso de Caspe: ¿Ruptura dinástica o modelo de Estado?”, Ruptura i legitimació dinàstica a l'Edat Mitjana, Lleida, 2012, pp. 279-290.

_ "Perpinyà, capital baixmedieval dels comtats de Rosseló i Cerdanya", La ciutat i els poders, Perpiñán, 2000, pp. 157-200.

— "Orden y desorden. La violencia en la cotidianidad bajomedieval catalana", Aragón en la Edad Media, 14-15 (1999), pp. 1389-1408.

_ "Discurs i estratègies del poder reial a Catalunya al segle XIV", Anuario de Estudios Medievales, 25/2 (1995), pp. 617-646.

_ "Les factions dans la vie urbaine de la Catalogne du XIVe siècle", Histoire et archéologie des terres catalanes au moyen âge, ed. Phillippe Sénac, Perpiñán, pp. 339-365.

Sesma Muñoz, José Ángel, "La fractura en la sociedad política catalana en vísperas del Compromiso de Caspe", Anuario de Estudios Medievales, 29 (1999), pp. 1043-1066.

Taylor, Quentin, "John of Salisbury, the Policraticus, and Political Thought", Humanitas, 19. 1/2 (2006), pp. 133-157.

Turull i Rubinat, Max, La configuració jurídica del municipi baix-medieval: règim municipal i fiscalitat a Cervera entre 1182-1430, Barcelona-Lleida, 1990.

Valdeón Baruque, Julio, "Los conflictos sociales en los siglos XIV y XV en la Península Ibérica", Anales de la Universidad de Alicante. Historia medieval, 3 (1984), pp. 131-142.

Viciano Navarro, Pau, "Violencia y sociedad en una villa medieval: Castellón de la Plana en el siglo XV", Hispania, 66 (2006), pp. 851-882.

Villanueva Morte, Concepción, Teruel en tiempos del Interregno y del Compromiso de Caspe según los manuales de actos del concejo (1410-1412)", El compromiso de Caspe (1412), cambios dinásticos y Constitucionalismo en la Corona de Aragón, coord. María Isabel Falcón, Zaragoza: Obra Social de Ibercaja, 2013, pp. 895-913.

Watts, John, La formación de los sistemas políticos, València, 2016. 